\title{
Ovarian cancer survival population differences: a "high resolution study" comparing Philippine residents, and Filipino-Americans and Caucasians living in the US
}

\author{
Maria Theresa M Redaniel ${ }^{\dagger 1}$, Adriano Laudico ${ }^{\dagger 2,3,4}$, Maria Rica Mirasol- \\ Lumague $^{\dagger 4}$, Adam Gondos ${ }^{\dagger 1}$, Gemma Leonora Uy ${ }^{\dagger 3}$, Jean Ann Toral ${ }^{\dagger 5}$, \\ Doris Benavides ${ }^{\dagger 5}$ and Hermann Brenner* ${ }^{\dagger 1}$
}

Address: ${ }^{1}$ Division of Clinical Epidemiology and Aging Research, German Cancer Research Center, Heidelberg, Germany, ${ }^{2}$ Manila Cancer Registry, Philippine Cancer Society, Manila, Philippines, ${ }^{3}$ Department of Surgery, Philippine General Hospital, University of the Philippines-Manila, Manila, Philippines, ${ }^{4}$ Department of Health-Rizal Cancer Registry, Rizal Medical Center, Pasig City, Philippines and ${ }^{5}$ Department of Obstetrics and Gynecology, Philippine General Hospital, University of the Philippines-Manila, Manila, Philippines

Email: Maria Theresa M Redaniel - m.redaniel@dkfz-heidelberg.de; Adriano Laudico - yago_md@yahoo.com; Maria Rica MirasolLumague - rdmsurgn@yahoo.com; Adam Gondos - a.gondos@dkfz.de; Gemma Leonora Uy - gemmauymd@yahoo.com; Jean Ann Toral - obonco@yahoo.com; Doris Benavides - dorisbenavides@yahoo.com; Hermann Brenner* - h.brenner@dkfz-heidelberg.de * Corresponding author †Equal contributors

Published: 24 September 2009

BMC Cancer 2009, 9:340 doi:10.1 I86/147|-2407-9-340
Received: 23 April 2009

Accepted: 24 September 2009

This article is available from: http://www.biomedcentral.com//47/-2407/9/340

(C) 2009 Redaniel et al; licensee BioMed Central Ltd.

This is an Open Access article distributed under the terms of the Creative Commons Attribution License (http://creativecommons.org/licenses/by/2.0), which permits unrestricted use, distribution, and reproduction in any medium, provided the original work is properly cited.

\begin{abstract}
Background: In contrast to most other forms of cancer, data from some developing and developed countries show surprisingly similar survival rates for ovarian cancer. We aimed to compare ovarian cancer survival in Philippine residents, Filipino-Americans and Caucasians living in the US, using a high resolution approach, taking potential differences in prognostic factors into account.

Methods: Using databases from the SEER I 3 and from the Manila and Rizal Cancer Registries, ageadjusted five-year absolute and relative survival estimates were computed using the period analysis method and compared between Filipino-American ovarian cancer patients with cancer patients from the Philippines and Caucasians in the US. Cox proportional hazards modelling was used to determine factors affecting survival differences.

Results: Despite more favorable distribution of age and cancer morphology and similar stage distribution, 5-year absolute and relative survival were lower in Philippine residents (Absolute survival, AS, 44\%, Standard Error, SE, 2.9 and Relative survival, RS, 49.7\%, SE, 3.7) than in FilipinoAmericans (AS, 5I.3\%, SE, 3.I and RS, 54.I\%, SE, 3.4). After adjustment for these and additional covariates, strong excess risk of death for Philippine residents was found (Relative Risk, RR, 2.45, $95 \%$ confidence interval, $95 \% \mathrm{Cl}, 1.99-3.01$ ). In contrast, no significant differences were found between Filipino-Americans and Caucasians living in the US.

Conclusion: Multivariate analyses disclosed strong survival disadvantages of Philippine residents compared to Filipino-American patients, for which differences in access to health care might have played an important role. Survival is no worse among Filipino-Americans than among Caucasians living in the US.
\end{abstract}




\section{Background}

Ovarian cancer is the second most common gynaecological cancer worldwide and the sixth most common cancer in women overall [1,2]. The majority of cancer cases occur in developed countries, and age standardized incidence and mortality rates are about two-fold higher in more affluent nations (10.2 and 5.7 per 100,000 population) as compared to less developed nations (5 and 2.9 per $100,000)$ [2]. However, there is large variation within both groups of countries. Within countries, ovarian cancer incidence and mortality have likewise been reported to vary between racial groups. The incidence rate of Philippine residents in 2002 was estimated at 11.5 per 100,000 [3] as compared to 10.3 for Caucasians and 8.9 for Asian and Pacific Islanders (API) in the United States [4]. Mortality rates were reported as 6.3 [3], 6 and 3.3 [4] per 100,000 for Philippine residents, Caucasians and APIs, respectively.

Comparisons in ovarian cancer survival between developed and developing nations, as well as between ethnic groups within countries, are few [5-7], but are important in determining sources of population survival discrepancies. In contrast to most other cancers, limited data from some developed and developing countries suggest that five-year relative survival rates were surprisingly similar, ranging from 31 to $42 \%$ and from 16 to $51 \%$, respectively [2]. In the US, non-Hispanic white women were reported to have reduced risk of death as compared to AfricanAmericans but have an increased risk compared to Filipino-American women [5]. However, previous comparative studies between developing and developed countries did not take into account potential differences in major prognostic factors, such as stage at diagnosis or morphology, which have been reported to vary between ethnic groups [5].

In this paper, we take a "high resolution" approach [8-10] to elucidate the role of factors not routinely available in population-based cancer registries, including ethnicity, stage at diagnosis, morphology, and access to treatment, in comparing ovarian cancer survival between Philippine resident patients, Filipino-Americans and Caucasians living in the US.

\section{Methods \\ Databases}

\section{United States SEER 13}

Using the Surveillance, Epidemiology and End Results (SEER) 13 database [4], ovarian cancer patients of Filipino-American or of Caucasian origin, including those of Hispanic ethnicity, were identified. Patients aged 15 and older, diagnosed with malignant ovarian cancer between January 1, 1993 and December 31, 2002 and followed with respect to vital status until December 31, 2002 were included in the study.

\section{Manila and Rizal Cancer Registries}

Patient information for residents of the National Capital Region (NCR) of the Philippines was abstracted from the Philippine Cancer Society-Manila Cancer Registry (PCSMCR) and the Department of Health-Rizal Cancer Registry (DOH-RCR). The registries are regarded as among the high-quality registries from developing countries and have consistently been included in the "Cancer Incidence in Five Continents" series [11-15]. They follow cancer registration definitions and data collection guidelines set by the International Agency for Research on Cancer (IARC) and the International Association of Cancer Registries (IACR) [16].

Using the same inclusion and exclusion criteria as for the SEER databases, a list of 2,898 ovarian cancer cases diagnosed between 1998 and 2002 was generated, from which sub samples of 200 cases diagnosed in each calendar year of interest were randomly drawn using the sample command in STATA version 6 [17]. Patients were followed with respect to vital status until December 31, 2002 as follows: survival status was assessed from death certificate notifications mentioning cancer as the cause of death, which were collected from Local Civil Registry Offices. For those not identified as dead, active follow-up by personal visits to the patients' last known place of residence were done to confirm vital status.

The project proposal was approved by the Ethics Review Board of the National Institutes of Health of the University of the Philippines Manila. The information obtained strictly conformed to the code of conduct stipulated by the Guidelines on Confidentiality for Population-based Cancer Registries [16].

\section{Data analysis}

Estimation of Survival using Period Analysis

To derive survival estimates, cohort-based analyses such as the conventional life-table (actuarial) method or the Kaplan-Meier method $[18,19]$ have traditionally been used. With the cancer database including cancer incidence and follow-up data from 1993 to 2002, a cohort based analysis would typically have pertained to patients diagnosed in 1993-1997 and followed through 2002 (see figure 1, framed area). To derive more up-to-date survival estimates, we employed period analysis, a new method of survival analysis introduced by Brenner and Gefeller in 1996 [20]. Here, only the survival experience of patients for the 1998-2002 period was included (see figure 1, shaded area). This was done by left truncation of observations at the beginning of the period and right censoring at its end (i.e. at December 31, 2002 or the last date known 


\begin{tabular}{|c|c|c|c|c|c|c|c|c|c|c|}
\hline Year of & & & & & ear of & ollow- & & & & \\
\hline diagnosis & 1993 & 1994 & 1995 & 1996 & 1997 & 1998 & 1999 & 2000 & 2001 & 2002 \\
\hline 1993 & 1 & $1 / 2$ & $2 / 3$ & $3 / 4$ & $4 / 5$ & 5 & & & & \\
\hline 1994 & & 1 & $1 / 2$ & $2 / 3$ & $3 / 4$ & $4 / 5$ & 5 & & & \\
\hline 1995 & & & 1 & $1 / 2$ & $2 / 3$ & $3 / 4$ & $4 / 5$ & 5 & & \\
\hline 1996 & & & & 1 & $1 / 2$ & $2 / 3$ & $3 / 4$ & $4 / 5$ & 5 & \\
\hline 1997 & & & & & 1 & $1 / 2$ & $2 / 3$ & $3 / 4$ & $4 / 5$ & 5 \\
\hline 1998 & & & & & & 1 & $1 / 2$ & $2 / 3$ & $3 / 4$ & $4 / 5$ \\
\hline 1999 & & & & & & & 1 & $1 / 2$ & $2 / 3$ & $3 / 4$ \\
\hline 2000 & & & & & & & & 1 & $1 / 2$ & $2 / 3$ \\
\hline 2001 & & & & & & & & & 1 & $1 / 2$ \\
\hline 2002 & & & & & & & & & & 1 \\
\hline
\end{tabular}

\section{Figure I}

Principle of period analysis. Database used to derive the cohort analysis estimates (solid frame) and period analysis estimates (shaded area). The numbers within the cells indicate the years of diagnosis

alive). It has been consistently shown by multiple empirical evaluations that period analysis provides more up-todate estimates of survival expectations for patients diagnosed in the respective period [21-25].

\section{Estimation of Relative Survival}

As commonly practiced in population-based cancer survival analysis, both absolute and relative survival rates were calculated. The relative survival probabilities are estimated as ratios of the observed survival of cancer patients and the expected survival of a group of people with the same age and sex distribution from the general population, and reflect the survival experience of cancer patients in the absence of competing causes of death [26,27]. Using the so-called Ederer II method [28], expected survival was derived from life tables for the year 2000. For the SEER populations, the life table for whites from the US National Center for Health Statistics [29] were used. The life table for the Philippine resident population was derived from the projected population estimate and the actual mortality data for this area, which were obtained from the Philippine National Statistics Office.

\section{Age adjustment}

To enable comparison of ovarian cancer survival estimates between different cancer populations, age adjustment was done. Age-specific period survival estimates (absolute and relative), using age groups 15-39, 40-49, 50-59, 60-69 and 70 and above, were first obtained from the Philippine res- ident, the Filipino-American and the Caucasian populations. The age-specific estimates were then weighted and summed for each population group, using weights from the World Standard Cancer Patient Population (WSCPP) [30].

Tests for survival differences between cancer patient populations The differences between survival estimates for the three cancer patient populations were tested for statistical significance using a novel modelling approach for period analysis [31]. First, age-specific numbers of patients at risk and of deaths by year of follow-up were calculated for each population group. Poisson regression models were then fitted, wherein the numbers of deaths were modelled as a function of the population group (entered as a categorical variable), year of follow-up $(1,2,3,4,5$ - entered as a categorical variable) and age-group (as described above - entered as a categorical variable), using the logarithm of the person-years at risk as offset, and accounting for late entries and withdrawals as half persons, as described in detail elsewhere. This allowed for testing of significance of differences in survival, after adjustment for age and based on p-values for the population parameter estimate. A significance level of alpha $=0.05$ (two-sided testing) was used.

\section{Multivariate analysis}

To explain possible survival differences and identify factors affecting survival, both within and between the three 
cancer patient populations, the Cox Proportional Hazards model was used. For each population group, bivariate associations of age, stage at diagnosis, histology, and receipt of surgery and of radiotherapy with survival were determined using individual Cox models. A multivariate model was then built jointly for all three groups to compare survival probabilities between populations. Relative hazards were calculated using Filipino-Americans as the reference group, while controlling for the effects of age, stage, histology, surgery and radiotherapy, first individually and then simultaneously. Those with missing information were excluded in the multivariate analysis. The assumption of proportional hazards for Cox models was checked by plotting the log of the negative log of the survival density functions vs the log of survival time. The plotted lines were roughly parallel over time and no violations of the proportional hazards assumption were found.

Age at diagnosis was categorized into the age adjustment groupings mentioned earlier. Stage categories were based on the Federation of Gynecology and Obstetrics (FIGO) stages I, II III and IV [32]. Histology was classified based on the International Classification of Diseases for Oncology (ICD-O) and the Systematized Nomenclature of Medicine [33] (serous, clear cell, endometrioid, mucinous and other types, including Brenner, granulosa cell, germ cell and sex cord stromal cell tumors). For the receipt of surgical treatment and of radiotherapy, binary variables (with/ without) were used. A sub-analysis for the receipt of chemotherapy was done for all the Philippine residents included in the study, but chemotherapy and hormone therapy were not included in the Cox models as these were not available from the SEER public use database.

All analyses were done with the SAS Statistical Analysis Software. Special macros were used for standard and modelled period survival analysis as previously described $[31,34]$.

\section{Results}

A total of 463 Filipino-American and 22,290 Caucasian ovarian cancer patients were included in the analysis, after exclusion of around $1 \%$ of cases who are coded in situ and those who were identified by death certificates only (DCO). From the 2,000 randomly sampled patients from the Philippine databases, 1,475 ovarian cancer patients (73.8\%) were included after 220 (11\%) and 305 (15.2\%) patients were removed due to invalid data, such as incorrect age, sex and primary site, and due to the absence of any survival time information, respectively. Of the included patients not known to be dead, complete 5-year follow-up information was obtained for $33.8 \%$, while at least some follow-up could be ascertained for another $41.3 \%$.
The distribution of cases by age groups, stage at diagnosis, histology, surgery and radiotherapy are shown for each population in Table 1. Caucasian patients were older than other groups, with more than $50 \%$ aged 60 or above while Philippine residents were youngest with more than $50 \%$ below 50 years. Around half of patients were diagnosed in the advanced stages (stages III and IV) in the Philippine resident population and Filipino-Americans, while the majority (66\%) of Caucasians presented with advanced stage disease. Histologic profile varied, with Caucasians having the highest proportion of serous cancers $(42 \%)$ and fewest proportions of endometrioid (14\%) and mucinous $(7 \%)$ types. Filipinos from the Philippines have the highest proportions of endometrioid (22\%) and mucinous $(24 \%)$ types with the smallest proportion of serous cancers $(20 \%)$. Between 78 and $90 \%$ of patients underwent surgery and less than $10 \%$ received radiotherapy in all groups. Of the Philippine resident patients with known chemotherapy status, $24 \%$ received this treatment.

Age adjusted and age-specific estimates of absolute and relative 5-year survival are shown in table 2 . Five-year over all relative survival was within a narrow range (49.3$54.1 \%$ ) in the three cancer patient populations. With few exceptions (which, given the relatively large standard errors in some of the age specific survival estimates, might be due to chance variation) relative survival decreased with age in all three cancer patient populations. Strong, statistically significant disadvantages in 5-year absolute and relative survival were seen in patients from the Philippines compared to Filipino-American patients in age groups 50-59 and 60-69.

As shown in table 3, late stage at diagnosis and not receiving surgery were all strongly related to the risk of dying in each of the three populations. Furthermore, compared to patients with serous cancers, prognosis tended to be substantially better in patients with endometrioid, clear cell and mucinous cancer, and less favorable in patients with other forms of cancer. A sub-analysis among the Philippine residents showed that not receiving chemotherapy was also related to the risk of death (RR, 1.54; 95\% CI 1.22-1.94).

In bivariate comparative survival analysis between population groups (table 4), substantial excess risk of death was seen among ovarian cancer patients from the Philippines and Caucasians as compared to Filipino-American patients. For Philippine residents, excess mortality was further increased when controlling for age and stage at diagnosis, and quite substantial excess mortality was found (RR, 2.45; 95\% CI, 1.99-3.01) after controlling for these and other factors in multivariate analysis. The excess risk of Caucasian ovarian cancer patients compared to Filipino-American ovarian cancer patients was mostly 
Table I: Tumor characteristics of ovarian cancer patients, Philippine resident population, and Filipino-Americans and Caucasians from US SEER, 1993-2002

\begin{tabular}{|c|c|c|c|c|c|c|c|}
\hline \multirow[t]{2}{*}{ Variable } & \multicolumn{2}{|c|}{$\begin{array}{l}\text { Philippine resident population } \\
\qquad(N=1475)\end{array}$} & \multicolumn{2}{|c|}{$\begin{array}{l}\text { Filipino-Americans } \\
\qquad(N=463)\end{array}$} & \multicolumn{2}{|c|}{$\begin{array}{l}\text { Caucasians } \\
(N=22290)\end{array}$} & \multirow[t]{2}{*}{ p-value } \\
\hline & Freq & $\% 1$ & Freq & $\% 1$ & Freq & $\% 1$ & \\
\hline \multicolumn{8}{|l|}{ Age group } \\
\hline$<40$ & 415 & 28.1 & 64 & 13.8 & 1545 & 6.9 & $<0.0001$ \\
\hline $40-49$ & 364 & 24.7 & 110 & 23.8 & 2948 & 13.2 & \\
\hline $50-59$ & 355 & 24.1 & 130 & 28.1 & 4356 & 19.5 & \\
\hline $60-69$ & 213 & 14.4 & 81 & 17.5 & 4787 & 21.5 & \\
\hline $70+$ & 128 & 8.7 & 78 & 16.9 & 8654 & 38.8 & \\
\hline \multicolumn{8}{|l|}{ FIGO } \\
\hline 1 & 316 & 33.5 & 160 & 35.9 & 4989 & 24.0 & $<0.0001$ \\
\hline II & 112 & 11.9 & 62 & 13.9 & 2013 & 9.7 & \\
\hline III & 315 & 33.4 & 138 & 30.9 & 8222 & 39.5 & \\
\hline IV & 201 & 21.3 & 86 & 19.3 & 5609 & 26.9 & \\
\hline Unknown & 531 & & 17 & & 1457 & & \\
\hline \multicolumn{8}{|l|}{ Morphology } \\
\hline Serous & 236 & 20.1 & 130 & 30.2 & 8520 & 42.4 & $<0.0001$ \\
\hline Clear cell & 72 & 6.1 & 44 & 10.2 & 974 & 4.9 & \\
\hline Endometrioid & 259 & 22.1 & 83 & 19.3 & 2897 & 14.4 & \\
\hline Mucinous & 285 & 24.3 & 45 & 10.5 & 1453 & 7.2 & \\
\hline Others & 320 & 27.3 & 128 & 29.8 & 6255 & 31.1 & \\
\hline $\mathrm{NOS}^{2}$ & 303 & & 33 & & 2191 & & \\
\hline \multicolumn{8}{|l|}{ Surgery } \\
\hline With surgery & 1214 & 88.6 & 396 & 85.7 & 17490 & 78.7 & $<0.0001$ \\
\hline Without surgery & 157 & 11.5 & 66 & 14.3 & 4743 & 21.3 & \\
\hline Unknown & 104 & & 1 & & 57 & & \\
\hline \multicolumn{8}{|l|}{ Radiotherapy } \\
\hline With radiotherapy & 95 & 7.7 & 12 & 2.6 & 437 & 2.0 & $<0.0001$ \\
\hline Without radiotherapy & 1144 & 92.3 & 445 & 97.4 & 21732 & 98.0 & \\
\hline Unknown & 236 & & 6 & & $12 \mid$ & & \\
\hline
\end{tabular}

'percentages refer to those with known categories

2includes: Neoplasms; Carcinoma, NOS; Carcinoma, Undifferentiated, NOS

explained by the age and stage differences, and no significant difference persisted in the multivariate analysis (RR, $1.17,95 \%$ CI, 0.99-1.37).

\section{Discussion}

In this "high resolution" study comparing ovarian cancer survival in the Philippine resident and Filipino-American patients, sharing the same ethnicity, and in FilipinoAmerican and Caucasian patients in the US, sharing the same health care system, overall survival differences were found to be relatively small. However, Philippine resident patients showed a more favorable distribution with respect to major prognostic factors, such as age, stage and morphology, and major excess mortality in this patient group was disclosed after control for these factors in age specific and multivariate analysis. By contrast, an appar- ent survival disadvantage of Caucasian patients compared to Filipino-American patients essentially disappeared after controlling for these factors. Taken together, these results point to the relevance of health care related factors for explaining survival differences.

Disadvantages in absolute and relative survival of Philippine residents compared to Filipino-Americans were particularly large for age groups 50-59 and 60-69, which can be explained to some extent by more unfavorable stage distributions. The proportions of patients presenting with advanced stages in age groups 50-59 and 60-69 were much lower in Filipino-Americans (48.4 and 55\%, respectively) than among Philippine residents (60.4 and 69.2\%, respectively). 
Table 2: Five-year absolute and relative survival (in \%) of ovarian cancer patients adjusted to the World Standard Cancer Patient Population, Philippine resident population, and Filipino-Americans and Whites from US SEER, 1998-2002

\begin{tabular}{|c|c|c|c|c|c|c|c|c|c|c|}
\hline \multirow[t]{2}{*}{ Variable } & \multicolumn{2}{|c|}{$\begin{array}{c}\text { (I) Philippine resident } \\
\text { population }\end{array}$} & \multicolumn{2}{|c|}{ Between (1) and (2) } & \multicolumn{2}{|c|}{ (2) Filipino-Americans } & \multicolumn{2}{|c|}{ Between (3) and (2) } & \multicolumn{2}{|c|}{ (3) Caucasians } \\
\hline & $\%$ & SE & Diff & p-value & $\%$ & SE & Diff & p-value & $\%$ & SE \\
\hline \multicolumn{11}{|l|}{$\begin{array}{l}\text { Absolute } \\
\text { Survival }\end{array}$} \\
\hline $\begin{array}{l}\text { Over all } \\
\text { survival }\end{array}$ & 44.0 & 2.9 & 7.4 & 0.02 & 51.3 & 3.1 & -4.6 & 0.29 & 46.7 & 0.5 \\
\hline \multicolumn{11}{|l|}{ Age group } \\
\hline$<40$ & 64.1 & 4.6 & 11.6 & 0.27 & 75.7 & 7.5 & 0.8 & 0.67 & 76.5 & 1.6 \\
\hline $40-49$ & 55.8 & 4.9 & -1.1 & 0.99 & 54.8 & 6.7 & 7.9 & 0.11 & 62.6 & 1.3 \\
\hline $50-59$ & 38.2 & 4.8 & 25.8 & $<0.001$ & 64.0 & 5.9 & -12.8 & 0.04 & 51.2 & I.I \\
\hline $60-69$ & 36.1 & 6.3 & 17.2 & 0.02 & 53.3 & 8.5 & -13.4 & 0.13 & 40.0 & 1.0 \\
\hline $70+$ & 34.6 & 8.0 & -12.7 & 0.03 & 21.9 & 6.0 & -2.6 & 0.86 & 19.3 & 0.6 \\
\hline \multicolumn{11}{|l|}{$\begin{array}{l}\text { Relative } \\
\text { Survival }\end{array}$} \\
\hline $\begin{array}{l}\text { Over all } \\
\text { survival }\end{array}$ & 49.7 & 3.7 & 4.5 & 0.01 & 54.1 & 3.4 & -4.8 & 0.33 & 49.3 & 0.5 \\
\hline \multicolumn{11}{|l|}{ Age group } \\
\hline$<40$ & 64.6 & 4.6 & 11.5 & 0.30 & 76.0 & 7.6 & 0.8 & 0.67 & 76.9 & 1.6 \\
\hline $40-49$ & 57.0 & 5.1 & -1.6 & 0.99 & 55.4 & 6.8 & 8.0 & 0.11 & 63.4 & 1.3 \\
\hline $50-59$ & 40.0 & 5.0 & 25.8 & $<0.001$ & 65.8 & 6.1 & -13.1 & 0.05 & 52.7 & I.I \\
\hline $60-69$ & 40.4 & 7.1 & 16.7 & 0.05 & 57.0 & 9.1 & -14.1 & 0.14 & 43.0 & 1.1 \\
\hline $70+$ & 50.8 & 11.7 & -23.0 & 0.03 & 27.8 & 7.6 & -2.6 & 0.74 & 25.2 & 0.8 \\
\hline
\end{tabular}

Diff, difference; SE, standard error

In the absence of effective screening methods, only a small proportion of ovarian cancer cases are diagnosed in early stages, where surgery alone will be effective $[32,35,36]$. Most cases were diagnosed as advanced disease, where chemotherapy is administered either as neo-adjuvant or adjuvant treatment $[32,35,36]$. The proportion of those given chemotherapy among Philippines residents is much lower than an estimated $65 \%$ for US patients [32], which is likely to be reflective of both the larger proportion of cases in later stages in US patients, and the poor access to chemotherapy among Philippine residents.

In developed countries, survival rates have improved in the recent decades [37-40], mainly due to progress in treatment, including the development of adequate debulking surgical procedures and effective chemotherapy regimens. Even with advanced stage, patients with no gross residual after the surgical debulking have a considerably better prognosis than those with minimal or extensive residual. The number of residual sites also appears to be important [41]. Current chemotherapy protocols are based on the experience of developed countries and its effectiveness do not necessarily translate in developing country settings, given the differences in resources and attitudes [42]. The availability and affordability of drugs differ between the developed and developing world, and complex chemotherapy regimens might not be feasible or affordable in low income nations [42]. Furthermore, patients might not complete prescribed regimens due to financial constraints [42], as most chemotherapy drugs are paid for privately in developing countries [43].

In the NCR, Philippines, adjuvant chemotherapy has been shown to improve survival [44]. However, while chemotherapy is available and at par with the western world, the distribution of specialized centers offering cancer care services is not proportionate, with most located in the major cities [45]. Moreover, most state of the art diagnostic and treatment facilities are situated in tertiary private hospitals, which typically are expensive and beyond the means of average citizens. While subsidized services are provided by government institutes, these are limited and represent only a fraction of the total number of hospitals.

Compounding the problem among Philippine residents is the persistent disbelief in chances to be cured from cancer [46]. In spite of health information campaigns, many in the country still perceive cancer as a highly fatal disease that leads to eventual death. When faced with high costs, difficult and long treatment process, and low or unsure chances of survival, many patients opt to either refuse or 
Table 3: Relative risk of death according to various prognostic factors among ovarian cancer patients, Philippine resident population and from Filipino-Americans and Caucasians from US SEER, 1993-2002, Bivariate analysis

\begin{tabular}{|c|c|c|c|c|c|c|}
\hline \multirow[t]{2}{*}{ Variable } & \multicolumn{2}{|c|}{ Philippine resident population } & \multicolumn{2}{|c|}{ Filipino-Americans } & \multicolumn{2}{|c|}{ Caucasians } \\
\hline & $\mathbf{R R}$ & $95 \% \mathrm{Cl}$ & $\mathbf{R R}$ & $95 \% \mathrm{Cl}$ & $\mathbf{R R}$ & $95 \% \mathrm{Cl}$ \\
\hline \multicolumn{7}{|l|}{ Age group } \\
\hline$<40$ & 1.00 & & 1.00 & & 1.00 & \\
\hline $40-49$ & 1.26 & $0.94-1.68$ & 1.82 & $1.01-3.28$ & 1.78 & $1.57-2.02$ \\
\hline $50-59$ & 1.80 & $1.37-2.36$ & 1.31 & $0.72-2.36$ & 2.50 & $2.22-2.81$ \\
\hline $60-69$ & 2.06 & $1.52-2.78$ & 1.84 & $0.98-3.44$ & 3.54 & $3.15-3.97$ \\
\hline $70+$ & 2.67 & $1.91-3.73$ & 4.08 & $2.29-7.28$ & 6.94 & $6.20-7.76$ \\
\hline \multicolumn{7}{|l|}{ FIGO Stage } \\
\hline 1 & 1.00 & & 1.00 & & 1.00 & \\
\hline II & 2.37 & $1.42-3.97$ & 2.28 & $1.20-4.34$ & 2.75 & $2.50-3.02$ \\
\hline III & 7.06 & $4.78-10.43$ & 5.23 & $3.19-8.57$ & 5.18 & $4.82-5.56$ \\
\hline IV & 14.28 & $9.59-21.26$ & 12.54 & $7.60-20.70$ & 9.08 & $8.45-9.75$ \\
\hline \multicolumn{7}{|l|}{ Morphology } \\
\hline Serous & 1.00 & & 1.00 & & 1.00 & \\
\hline Endometrioid & 0.80 & $0.48-1.31$ & 0.51 & $0.27-0.98$ & 0.61 & $0.54-0.68$ \\
\hline Clear cell & 0.85 & $0.61-1.18$ & 0.50 & $0.30-0.83$ & 0.51 & $0.48-0.55$ \\
\hline Mucinous & 0.67 & $0.47-0.95$ & 0.46 & $0.23-0.90$ & 0.61 & $0.56-0.67$ \\
\hline Others & 1.55 & $1.16-2.07$ & 1.14 & $0.79-1.65$ & 1.55 & $1.49-1.62$ \\
\hline \multicolumn{7}{|l|}{ Surgery } \\
\hline With surgery & 1.00 & & 1.00 & & 1.00 & \\
\hline Without surgery & 3.10 & $2.44-3.94$ & 6.30 & $4.50-8.82$ & 5.18 & $4.97-5.39$ \\
\hline \multicolumn{7}{|l|}{ Radiotherapy } \\
\hline With radiotherapy & 1.00 & & 1.00 & & 1.00 & \\
\hline Without radiotherapy & 1.25 & $0.87-1.79$ & 1.20 & $0.44-3.26$ & 1.25 & $1.09-1.43$ \\
\hline
\end{tabular}

RR, Relative Risk; 95\% Cl, 95\% Confidence interval

Table 4: Relative risk of death for ovarian cancer patients from the Philippine resident population and for Caucasian patients compared to Filipino-American patients from US SEER, 1993-2002

\begin{tabular}{|c|c|c|c|c|c|c|}
\hline \multirow[t]{2}{*}{ Variable } & \multicolumn{2}{|c|}{ Philippine resident population } & \multicolumn{2}{|c|}{ Filipino-Americans (reference group) } & \multicolumn{2}{|c|}{ Caucasians } \\
\hline & $\mathbf{R R}$ & $95 \% \mathrm{Cl}$ & $\mathbf{R R}$ & $95 \% \mathrm{Cl}$ & $\mathbf{R R}$ & $95 \% \mathrm{Cl}$ \\
\hline Bivariate analysis & 1.46 & $1.23-1.74$ & 1.00 & --- & 1.53 & $1.32-1.77$ \\
\hline \multicolumn{7}{|c|}{ After controlling for other variables } \\
\hline Age & 1.82 & $1.53-2.16$ & 1.00 & --- & 1.17 & $1.01-1.36$ \\
\hline FIGO Stage & 1.77 & $1.48-2.13$ & 1.00 & --- & 1.19 & $1.02-1.39$ \\
\hline Morphology & 1.66 & $1.38-2.01$ & 1.00 & --- & 1.49 & $1.27-1.75$ \\
\hline Surgery & 1.44 & $1.21-1.71$ & 1.00 & --- & 1.41 & $1.22-1.64$ \\
\hline Radiotherapy & 1.60 & $1.34-1.91$ & 1.00 & -- & 1.55 & $1.34-1.80$ \\
\hline Multivariate analysis' & 2.45 & $1.99-3.01$ & 1.00 & --- & 1.17 & $0.99-1.37$ \\
\hline
\end{tabular}

RR, Relative Risk; $95 \% \mathrm{Cl}$, 95\% Confidence interval

'Controlling for all variables listed in the table 
discontinue any form of therapy when it becomes an excessive burden.

While much of the differences are likely to be explained by health care access, dissimilar distributions by age, stage and histology suggest a possible role of biological factors. The differences in tumor biology between populations might be reflective of the heterogeneous nature of ovarian cancer, and should be investigated in more detail, given that previous studies have shown significant variation of survival by histologic subtypes [5,47-49].

Between Filipino-Americans and Caucasians, slightly higher absolute and relative survival rates were observed for the former group. The distributions by age and stage at diagnosis vary between the groups, with Filipino-Americans having more favorable characteristics. The Cox model showed that the higher proportion of Caucasian women with older age and advanced disease explains most of the apparent survival difference. After adjustment for these variables, as well as morphology and treatment, the residual excess risk was small (15\%) and not significant. Sensitivity analyses regarding difference in survival estimates between Caucasian population with and without Hispanics did not show a significant difference.

Our study is limited to variables that were available and comparable in the databases, and not all possible factors that could affect survival were considered. Information on chemotherapy is not included in the SEER public use database whereas some tumor characteristics such as grade, size and heterogeneity were not available from the Philippine database. In addition, socio-economic status, family history of ovarian cancer and lifestyle factors, like contraceptive use and hormone intake, were also not studied. Similarly, more detailed information on health care access, particularly on access to and availability of various treatment regimens, as well as application of treatment guidelines, protocols used, specialization and expertise of treating physicians, were not obtainable.

Patients with invalid data and those who do not have follow-up time were excluded from the study, but it is unlikely that they have higher survival than those who were included. Most such patients have incomplete records and were not traced to other hospitals in the NCR, indicating that they might not have consulted physicians after the initial diagnosis, or have had limited consultations afterwards. They most probably have not received any form of treatment as the availability of cancer treatment is limited outside the NCR. The survival rates presented might therefore overestimate true survival of Philippine residents to some extent.

\section{Conclusion}

In conclusion, the results of the multivariate analyses disclosed strong survival disadvantages of Philippine residents compared to Filipino-American patients, despite similar overall survival rates observed in the presence of more favorable distributions of major prognostic factors. The survival disadvantage of Philippine resident patients most likely reflects differences in access to and affordability of effective health care and treatment, such as chemotherapy. Emphasis should therefore be given on improving access to and affordability of effective treatment regimens. Prognosis is no worse among FilipinoAmericans than among Caucasians living in the US.

\section{List of Abbreviations used}

API: Asian and Pacific Islanders; AS: Absolute survival; DCO: Death certificates only; DOH-RCR: Department of Health-Rizal Cancer Registry; EUROCARE: European cancer registry-based study on survival and care of cancer patients; FIGO: Federation of Gynecology and Obstetrics; RR: Relative risk; IACR: International Association of Cancer Registries; IARC: International Agency for Research on Cancer; ICD-O: International Classification of Diseases for Oncology; NCR: National Capital Region; PCS-MCR: Philippine Cancer Society-Manila Cancer Registry; RS: Relative survival; SE: Standard error; SEER: Surveillance, Epidemiology and End Results; WSCPP: World Standard Cancer Patient Population; US: United States

\section{Competing interests}

The authors declare that they have no competing interests.

\section{Authors' contributions}

The contributions of the authors are as follows: MTR contributed in the planning of the study, supervised data collection, performed the analysis and wrote the manuscript; AL, MRL, GU, JT and DB planned and supervised data collection, reviewed and edited registry abstracts, and performed data management; AG assisted in the analysis; $\mathrm{HB}$ contributed in the planning of the study and supervised data analysis and writing of the manuscript. All authors have read and approved the final manuscript.

\section{Acknowledgements}

Our thanks go out to the staff of the Manila and Rizal Cancer Registries (Siony Alcos, Zoila Bautista, Lydia Navarro, Ellen Santos, Antonette Tad-y, Minda Turano, Melinda Visoria, Wilma Grafilo, Tess Medes, Herly SyMenco, Elena Marquez, Josephine Isla, Portia de Guzman and Arlene Sasot) who facilitated data abstraction and patient follow-up. We also thank Mr. Vincent Olaivar of the NSO for his help in obtaining population information and Ms. Editha Dumo of the National Economic and Development Authority (NEDA) for her assistance in obtaining mortality data and report on the NCR profile. Special mention also goes to the Philippine Cancer Society and the Rizal Medical Center. The work of Maria Theresa Redaniel was supported by a scholarship from the German Academic Exchange Service (DAAD). 


\section{References}

I. Parkin D, Bray F, Ferlay J, Pisani P: Global cancer statistics, 2002. CA Cancer J Clin 2005, 55:74- I08.

2. Sankaranarayanan R, Ferlay J: Worldwide burden of gynaecological cancer: the size of the problem. Best practice \& research 2006, 20(2):207-225.

3. GLOBOCAN 2002: Cancer Incidence, Mortality and Prevalence Worldwide. IARC CancerBase No. 5. version 2.0. Lyon: IARCPress; 2004.

4. Surveillance Epidemiology and End Results (SEER) Program: LimitedUse Data (1973-2005) National Cancer Institute, DCCPS, Surveillance Research Program, Cancer Statistics Branch, released April 2008, based on the November 2007 submission. [http://www.seer.cancer.gov]

5. McGuire V, Jesser CA, Whittemore AS: Survival among U.S. women with invasive epithelial ovarian cancer. Gynecologic oncology 2002, 84:399-403.

6. Gondos A, Brenner $H$, Wabinga $H$, Parkin D: Cancer survival in Kampala, Uganda. Br / Cancer 2005, 92:1808-I8I2.

7. Redaniel MT, Laudico A, Mirasol-Lumague MR, Gondos A, Pulte D, Mapua $\mathrm{C}$, Brenner $\mathrm{H}$ : Cancer survival discrepancies in developed and developing countries: comparisons between the Philippines and the United States. Br J Cancer 2009, I 00(5):858-862.

8. Gatta G, Capocaccia R, Sant M, Bell CM, Coebergh JW, Damhuis RA Faivre J, Martinez-Garcia C, Pawlega J, Ponz de Leon M, Pottier D, Raverdy N, Williams EM, Berrino F: Understanding variations in survival for colorectal cancer in Europe: a EUROCARE high resolution study. Gut 2000, 47(4):533-538.

9. Sant M, Aareleid T, Artioli ME, Berrino F, Coebergh JW, Colonna M, Forman D, Hedelin G, Rachtan J, Lutz JM, Otter R, Raverdy N, Plesko II, Primic MZ, Tagliabue G: Ten-year survival and risk of relapse for testicular cancer: a EUROCARE high resolution study. Eur J Cancer 2007, 43(3):585-592.

10. Berrino F: The EUROCARE Study: strengths, limitations and perspectives of population-based, comparative survival studies. Ann Oncol 2003, I4(Suppl 5):v9-I3.

II. Muir C, Waterhouse J, Powell J, Mack T, Whelan S, eds: Cancer Incidence in Five Continents. Volume V. Lyon: International Agency for Research on Cancer; 1987.

12. Parkin D, Muir C, Whelan S, Gao Y, Ferlay J, Powell J, eds: Cancer Incidence in Five Continents. Volume VI. Lyon: International Agency for Research on Cancer; 1992.

13. Parkin D, Whelan S, Ferlay J, Raymond L, Young J, eds: Cancer Incidence in Five Continents. Volume VII. Lyon: International Agency for Research on Cancer; 1997.

14. Parkin D, Whelan S, Ferlay J, Teppo L, Thomas D, eds: Cancer Incidence in Five Continents. Volume VIII. Lyon: International Agency for Research on Cancer; 2002.

15. Curado M, Edwards B, Shin H, Storm H, Ferlay J, Heanue M, Boyle P, eds: Cancer Incidence in Five Continents. Volume IX. IARC Scientific Publications No. I60 Lyon: IARC; 2007.

16. International Association of Cancer Registries, International Agency for Research on Cancer: Guidelines On Confidentiality For Population-based Cancer Registries, Internal Report No. 2004 03. Lyon: IARC; 2004:20-26.

17. Stata Statistical Software: Release 6.0. College Station, Texas: Stata Corp; 1999.

18. Cutler S, Ederer F: Maximum utilization of the life table method in analyzing survival. I Chron Dis 1958, 8:699-712.

19. Kaplan E, Meier P: Nonparametric estimation from incomplete observations. J Am Stat Assoc 1958, 53:457-48I.

20. Brenner $\mathrm{H}$, Gefeller $\mathrm{O}$ : An alternative approach to monitoring cancer survival. Cancer 1996, 78:2004-2010.

21. Brenner H, Hakulinen T: Up-to-date long-term survival curves of patients with cancer by period analysis. J Clin Oncol 2002, 20:826-832.

22. Brenner $\mathrm{H}$, Hakulinen $\mathrm{T}$ : Advanced detection of time trends in long-term cancer patient survival: experience from 50 years of cancer registration in Finland. Am J Epidemiol 2002, I 56:566-577.

23. Brenner $H$, Soderman $B$, Hakulinen $T$ : Use of period analysis for providing more up-to-date estimates of long-term survival rates: empirical evaluation among 370,000 cancer patients in Finland. Int J Epidemiol 2002, 3 I:456-462.
24. Tälback M, Stenbeck M, Rosen M: Up-to-date long-term survival of cancer patients: an evaluation of period analysis on Swedish Cancer Registry data. Eur J Cancer 2004, 40: I 36 I- I 372.

25. Ellison L: An empirical evaluation of period survival analysis using data from the Canadian Cancer Registry. Ann Epidemiol 2006, 16:191-196

26. Ederer $F$, Axtell LM, Cutler SJ: The relative survival rate: a statistical methodology. National Cancer Institute monograph 196I, 6: $|0|-|2|$.

27. Henson DE, Ries LA: The relative survival rate. Cancer 1995 , 76:1687-1688.

28. Ederer $\mathrm{F}$, Heise $\mathrm{H}$ : Instructions to IBM 650 programmers in processing survival computations. Bethesda, MD: National Cancer Institute; 1959.

29. Arias E: United States abridged life tables, 2000. National vita statistics reports; vol 5 I no 3 . Hyattsville, Maryland: National Center for Health Statistics; 2002.

30. Sankaranarayanan R, Black R, Parkin D: Cancer Survival in Developing Countries. Lyon: International Agency for Research on Cancer; 1998.

31. Brenner $\mathrm{H}$, Hakulinen T: Up-to-date and precise estimates of cancer patient survival: model-based period analysis. Am J Epidemiol 2006, I 64:689-696.

32. Heintz AP, Odicino F, Maisonneuve P, Quinn MA, Benedet JL, Creasman WT, Ngan HY, Pecorelli S, Beller U: Carcinoma of the ovary. FIGO 6th Annual Report on the Results of Treatment in Gynecological Cancer. Int J Gynaecol Obstet 2006, 95(Suppl I):S16I-192.

33. Tavassoli F, Deveilee P: World Health Organization Classification of Tumours. Pathology and Genetics of Tumours of the Breast and Female Genital Organs. Lyon: IARC Press; 2003.

34. Brenner H, Gefeller O, Hakulinen T: Period analysis for 'up-todate' cancer survival data: theory, empirical evaluation, computational realisation and applications. Eur J Cancer 2004, 40:326-335

35. Hensley ML: Epithelial ovarian cancer. Curr Treat Options Oncol 2002, 3(2):|3|-|4|.

36. Ozols RF: Update on the management of ovarian cancer. Cancer J 2002, 8(SuppI I):S22-30

37. Gondos A, Bray F, Hakulinen T, Brenner H: Trends in cancer survival in I I European populations from I 990 to 2009: a modelbased analysis. Ann Oncol 2009, 20(3):564-573.

38. Cooper N, Quinn MJ, Rachet B, Mitry E, Coleman MP: Survival from cancer of the ovary in England and Wales up to $200 \mathrm{I}$. $\mathrm{Br}$ J Cancer 2008, 99(Suppl I):S70-72.

39. Karim-Kos HE, de Vries E, Soerjomataram I, Lemmens V, Siesling S, Coebergh JW: Recent trends of cancer in Europe: a combined approach of incidence, survival and mortality for 17 cancer sites since the 1990s. Eur J Cancer 2008, 44( I 0): I 345-I389.

40. Verdecchia A, Guzzinati S, Francisci S, De Angelis R, Bray F, Alleman C, Tavilla A, Santaquilani M, Sant M: Survival trends in European cancer patients diagnosed from 1988 to 1999. Eur J Cancer 2009, 45(6): 1042-1066.

41. Greene FL, Page DL, Fleming ID, Fritz AG, Balch C, Haller DG, Morrow M, eds: AJCC Cancer Staging Manual Sixth Edition. New York-Berlin-Heidelberg: Springer-Verlag; 2002

42. Basile S, Angioli R, Manci N, Palaia I, Plotti F, Benedetti Panici P: Gynecological cancers in developing countries: the challenge of chemotherapy in low-resources setting. Int / Gynecol Cancer 2006, I6(4): |49|-|497.

43. Mellstedt $\mathrm{H}$ : Cancer initiatives in developing countries. Ann Oncol 2006, I7(Supplement 8):viii24-viii3I.

44. Garcia V, Toral J, Siasu M: Malignant ovarian germ cell tumors: clinical characteristics, treatment and outcome. The experience in a tertiary government institution. Philipp J Gyn Oncol 2008, 5:54-63.

45. NSCB: Metro Manila - a Gateway to the Philippines, 2005 Edition. Makati: National Statistical Coordinating Board; 2006.

46. Pisani P, Parkin D, Ngelangel C, Esteban D, Gibson L, Munson M, Reyes $M$, Laudico A: Outcome of screening by clinical examination of the breast in a trial in the Philippines. Int J Cancer 2006, I | 8: | 49 -154.

47. Ikeda K, Sakai K, Yamamoto R, Hareyama H, Tsumura N, Watari H, Shimizu M, Minakami $H$, Sakuragi N: Multivariate analysis for prognostic significance of histologic subtype, GST-pi, MDR- 
I, and p53 in stages II-IV ovarian cancer. Int / Gynecol Cancer 2003, I3:776-784.

48. Ji J, Forsti A, Sundquist J, Lenner P, Hemminki K: Survival in ovarian cancer patients by histology and family history. Acta oncologica (Stockholm, Sweden) 2008, 47(6): I I33-I I 39.

49. Chan JK, Teoh D, Hu JM, Shin JY, Osann K, Kapp DS: Do clear cell ovarian carcinomas have poorer prognosis compared to other epithelial cell types? A study of I4I I clear cell ovarian cancers. Gynecologic oncology 2008, 109:370-376.

\section{Pre-publication history}

The pre-publication history for this paper can be accessed here:

http://www.biomedcentral.com/1471-2407/9/340/pre pub

Publish with Bio Med Central and every scientist can read your work free of charge

"BioMed Central will be the most significant development for disseminating the results of biomedical research in our lifetime. "

Sir Paul Nurse, Cancer Research UK

Your research papers will be:

- available free of charge to the entire biomedical community

- peer reviewed and published immediately upon acceptance

- cited in PubMed and archived on PubMed Central

- yours - you keep the copyright

Submit your manuscript here:

http://www.biomedcentral.com/info/publishing_adv.asp 